\title{
Electrokinetic Desalination of Compound Building Materials by Applying Electric Field
}

\author{
Muhammad Yasir*, Muhammad Ayyaz, Kashif Kamran, Mubashra Ishaq, Farhan Rasool \\ Department of Physics, University of Agriculture, 38040 Faisalabad, Pakistan \\ E-mail: yasirmajeed707@gmail.com (Corresponding author); muhammadayyaz333@yahoo.com; \\ k.kamran@uaf.edu.pk
}

Received: 29 May 2021; Accepted: 11 June 2021; Available online: 25 June 2021

\begin{abstract}
Damaging of building materials is directly connected to the salt crystallization. The present research is based on removal of $\mathrm{NaCl}$ from compound building materials, where a direct current (DC) electric field was applied to the mortar plus bricks system. The main objective of this work is to investigate the electrokinetic desalination methodology that can provide sufficient removal of salts. $\mathrm{pH}$ neutralization in the surrounding of mortar plus bricks system is crucial to obtain sufficient desalination. For this purpose, the electrodes across the brick were inserted in kaolin clay mixed with buffer agents to suppress the $\mathrm{pH}$ changes. Most of the experiments were performed with kaolin clay and sponge. The concentration of chloride ions and sodium ions in all the segments and clay poultice was measured using argentometric titration method and flame photometer, whereas the $\mathrm{pH}$ variations in the entire system was measured by using $\mathrm{pH}$ indicator papers. The electrokinetic desalination was found to be an efficient method as $86 \%$ removal of chloride and $80 \%$ removal of sodium was achieved.
\end{abstract}

Keywords: Electrokinetic desalination; DC electric field; Compound building materials.

\section{Introduction}

Fired-clay bricks are an important part of building materials. These are used for construction of Masajids, railway stations, gardens, private houses and many other buildings. The bricks are appreciated in the entire world, but regrettably many bricks suffer from severe decay, especially those classified as culture heritage. The crystallization of water soluble salts play a main role in the decay in both modern and historical buildings [1-3]. The crystallization of salts take place in the pores of porous materials and they increase the pressure on wall of building materials, cause to damage the building materials. The crystallization of salt decreases the life of building and building materials and building materials lose their attraction [4]. The damage to the building material requires the completion of an intervention that safeguards the building, especially culture heritage where the loss of materials can be considered unacceptable.

Since salts removal in building materials was investigated by applying different techniques such as poultices or sacrificial mortars. Which allow the mobilization of salts through both advection and diffusion mechanism [5]. This technique has some limitations: 1 ) the pores distribution is different in every building material thus poultices have low extraction capacity (for fired-clay brick it is hardly $20 \mathrm{~mm}$ ) at deep level due to pores distribution. 2) They have low rate of transport of salts ions (1). In the last few years, electrokinetic have been invested for overcome the limitation of poultices techniques. In the electrokinetic technique a Direct Current (DC) filed applying for the removal of salts. It has been seemed in the experiments that the removal rate of salts higher than the other techniques (poultices or sacrifices mortars). When an electric DC field is applied to the porous building materials, the electric current transport the ions to their respective electrodes [6].

During the electrokinetic investigation, $\mathrm{pH}$ values vary at both electrodes due to electrolysis of water. During the electrolysis of water acid formed at anode and alkaline at cathode (Eqs, (1) and (2)).

$$
\begin{aligned}
& \mathrm{H}_{2} \mathrm{O} \rightarrow 2 \mathrm{H}^{+}+\frac{1}{2} \mathrm{O}_{2(g)}+2 e^{-} \\
& 2 \mathrm{H}_{2} \mathrm{O}+2 e^{-} \rightarrow 2 \mathrm{OH}^{-}+\mathrm{H}_{2(g)}
\end{aligned}
$$

These $\mathrm{pH}$ changes play and important role, they can cause new several chemicals (acidic and alkaline), results in an inefficient electrical transport process due to the high production of hydroxides $\mathrm{OH}^{-}$ions at the cathode and protons $\mathrm{H}^{+}$ions at anode. This $\mathrm{pH}$ change may affect the material and reduce the desalination capacity of the treatment [7]. 
To avoid that these $\mathrm{pH}$ changes, the use of buffer electrolytes (sodium/acid citrate or acetic acid/sodium acetate). This technique increases the process and also avoid the effects of $\mathrm{pH}$ changes on the treated materials. In this technique, the anode is usually used a poultice made of kaolin and calcium carbonate or magnesium carbonate, the cathode is used a poultice made of kaolin and acid acids [8]. When we used the buffering agents in the electrokinetic treatments, the electroosmosis occurs from the anode towards cathode in the porous building materials. This phenomenon dries the anode faster than the cathode which is located between materials and poultice, which cause decrease the flow of ions to their respectively electrodes [9]. To solve this problem poultice must remain moist to ensure good contact with electrode and with the materials to be treated. For this purpose, introduced a sponge between electrode and materials. This modulating capacity makes it possible to buffer the $\mathrm{pH}$ to the desired value and improved the current flow [10].

In the present work, the main aim is determining the effect of electro-kinetics on the brick plus mortar system and desalination of brick plus mortar system. This study concentrates on the impact on transportation procedures of boundary conditions (brick and mortar). The purpose of this work is to illustrate electro-kinetic removal of sodium chloride from brick plus mortar system. Furthermore, the role of buffering agents on the removal efficiency and to suppress the $\mathrm{pH}$ changes is also investigated [11].

\section{Materials and methods}

\section{1 Brick and mortar samples}

In this study we used mortar plus brick system. The bricks used in the laboratory experiment were new from the brickwork with porosity 30.77 \% which is situated at medina town Faisalabad, Punjab Pakistan. We removed outer layer of the brick about $1 \mathrm{~cm}$ in order to obtain homogeneous samples by wet cutting [12]. After homogeneous cutting of the brick was cut into two equal parts $3 \mathrm{~cm}$ in length, $2 \mathrm{~cm}$ in height and $3.5 \mathrm{~cm}$ in width. In order to join these two parts of brick together, we used a $1.5 \mathrm{~cm}$ thick layer of mortar with porosity $8 \%$. The samples were dried at $110^{\circ} \mathrm{C}$ for 24 hours (2). These samples were submerged with $2 \mathrm{M} \mathrm{NaCl}$ solution for 25 days to get capillary saturation (the maximum extent up to which a mortar plus brick or any porous materials can absorb moisture). After 25 days the weight of the wet mortar plus bricks was also measured. The mortar plus bricks system is shown in fig 1.

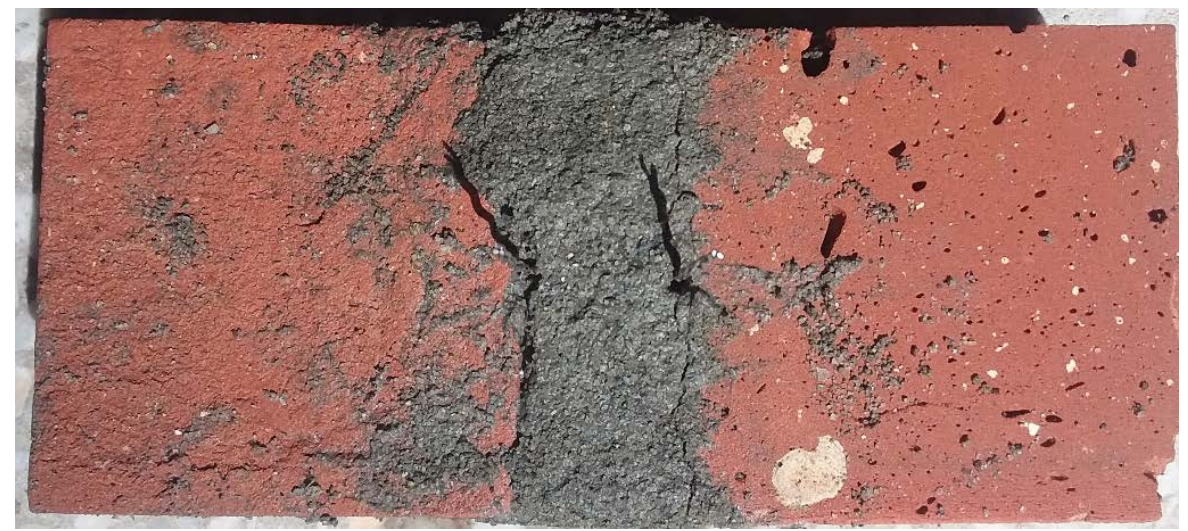

Fig 1. Mortar plus bricks system.

\subsection{Experimental setup}

After contaminating brick plus mortar system in the $\mathrm{NaCl}$ solution, the samples were covered with tape to minimize evaporation during treatment and samples placed in electro-kinetic setup for desalination treatment. The electro-kinetic cell in this study was used to $9 \mathrm{~cm}$ long, $4.2 \mathrm{~cm}$ wide and its height is $2.5 \mathrm{~cm}$. At both sides of brick plus mortar system were filled with clay poultice in EK cell and the electrodes inserted in this clay poultice. During the electro-kinetic experiment electric potential variation across the brick plus mortar system were measured using data-acquisition system [13].

A total of 5 bricks plus mortar samples were used. As the analysis of the samples was destructive, at the experiments were conducted with same conditions, same duration and same voltage. One of the samples was left as reference (no applied electric DC field). One of the experiments was conduct only applied clay around the sample for 24 hours. The other 3 samples were submitted to a constant voltage of 9 Volt for 24 hours. We were drilled in the bricks for placed the electrodes (tungsten with a diameter $3 \mathrm{~mm}$ ) in the bricks plus mortar system. The electrodes (mash with diameter $5 \mathrm{~mm}$ ) applied around the sample for given the voltage to the sample. One the experiment was contact only use sponge in the electrode compartment. In the second experiment the electrode compartments were filled with clay and sponge applied between sample and electrode. In the last experiment the 
electrode chambers were filled with clay and buffering agent (at anode side calcium carbonate $\left(\mathrm{CaCO}_{3}\right)$ was used as a buffering agent and at the cathode side acetic acid was used as a buffering agent) [14] and sponge applied between sample and electrode. Clay was chosen due to the high carbonate content of about $17 \%$. The whole setup of electrokinetic desalination is shown in fig 2.

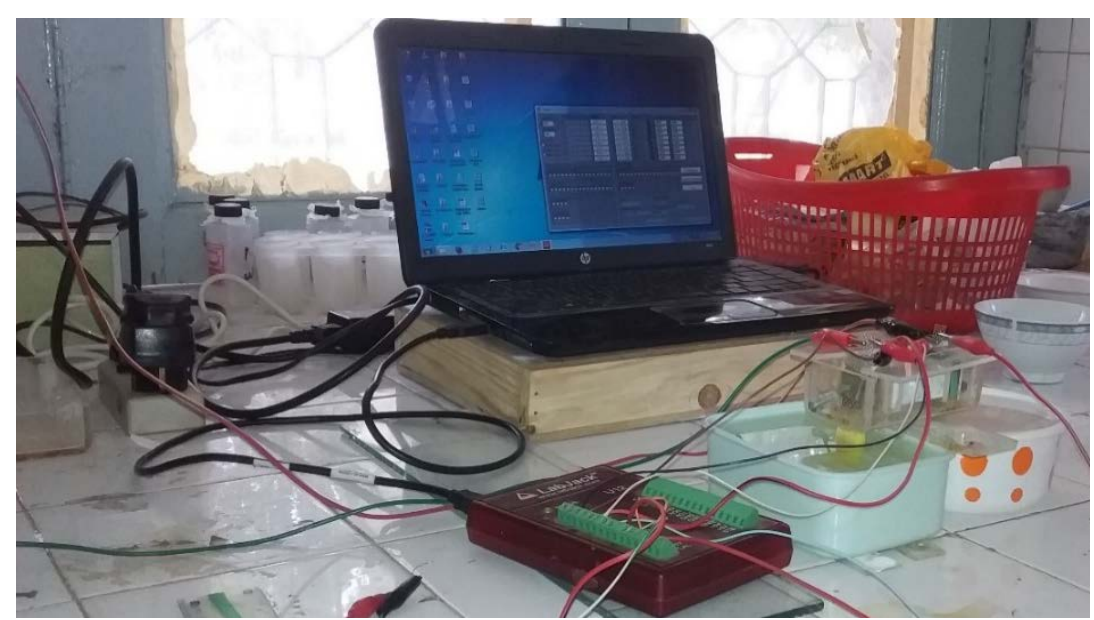

Fig 2. The whole setup of electrokinetic desalination

After the treatments the brick plus mortar system were cut into 5 segments approximately the same size left to right which is shown in fig 3 . The segmentation was done with hammer and chisel with hand. The water contact was measured for each segment by weighting before and after drying. Each segment was crush into powder by hand. The concentration of chloride ions and sodium ions in all the segments of mortar plus brick system and clay poultice was measured with this powder.

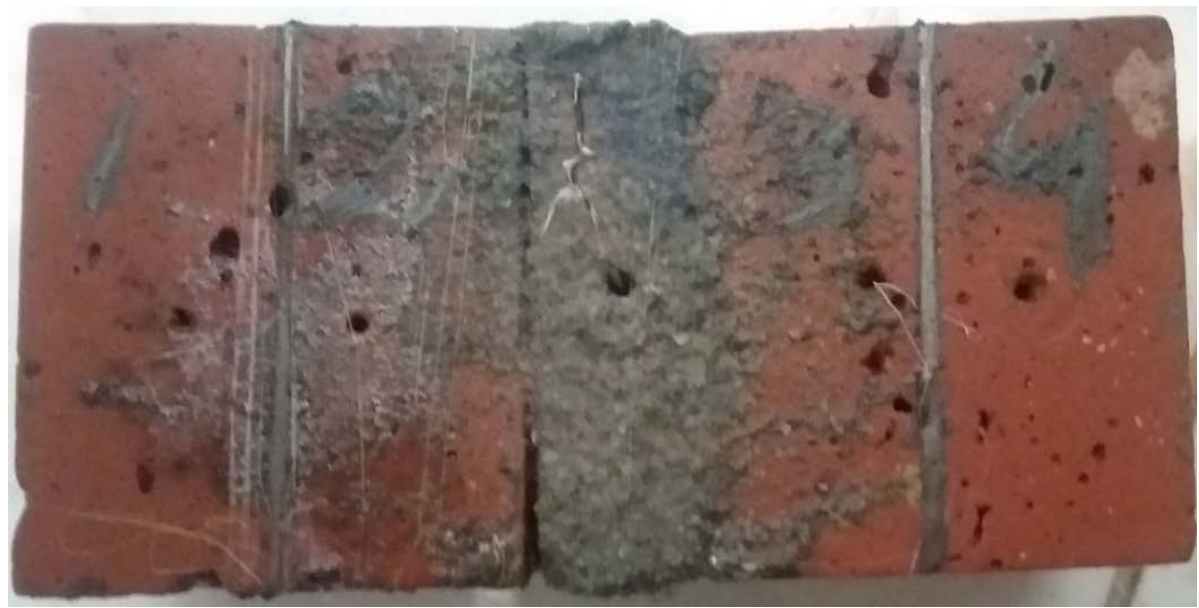

Fig 3. Mortar plus bricks system were cut into 5 segments

\subsection{Analysis}

To the investigation of $\mathrm{Na}^{+}$and $\mathrm{Cl}^{-}$The bricks plus mortar materials was powdered. Extractions were made with $5 \mathrm{~g}$ dry powder and $25 \mathrm{ml}$ distilled water. After making the extraction, the prepared extraction was placed on shaking table for 1 hour. After shaking, the extractions were filtrated through $0.45 \mu \mathrm{m}$ filter paper [15]. The concentration of chloride ions and sodium ions in all the segments of mortar plus brick system and clay poultice was measured using Argentometric titration method and flame photometer, whereas the $\mathrm{pH}$ variations in the entire system was measured by using $\mathrm{pH}$ indicator papers [16].

\subsection{Experiment series}

In table 1, the weight of each piece of brick are given before and after submerging in $\mathrm{NaCl}$ solution. The conducted reference and electrokinetic experiment are outlined are also given in table 1 by the parameters types of salts voltage and duration. 
Table 1. The weight of each piece of brick before and after submerging in $\mathrm{NaCl}$ solution.

\begin{tabular}{cccccccc}
\hline Sr. No & $\begin{array}{c}\text { Weight dry } \\
\text { brick (g) }\end{array}$ & Salt & $\begin{array}{c}\text { Weight wet } \\
\text { brick (g) }\end{array}$ & $\begin{array}{c}\text { Sr. no } \\
\text { Weight dry } \\
\text { brick (g) }\end{array}$ & $\begin{array}{c}\text { Salt } \\
\text { Weight wet } \\
\text { brick (g) }\end{array}$ \\
\hline 1 & 50.62 & $\mathrm{NaCl}$ & 58.06 & 2 & 50.11 & $\mathrm{NaCl}$ & 57.86 \\
3 & 49.72 & $\mathrm{NaCl}$ & 56.80 & 4 & 49.38 & $\mathrm{NaCl}$ & 57.86 \\
5 & 48.95 & $\mathrm{NaCl}$ & 56.03 & 6 & 48.91 & $\mathrm{NaCl}$ & 57.49 \\
7 & 49.26 & $\mathrm{NaCl}$ & 56.95 & 8 & 49.85 & $\mathrm{NaCl}$ & 57.02 \\
9 & 50.37 & $\mathrm{NaCl}$ & 59.40 & 10 & 49.14 & $\mathrm{NaCl}$ & 56.81 \\
\hline
\end{tabular}

\section{Results and discussion}

\subsection{Electrokinetic experiments}

Three experiments were conducted with same voltage and different conditions to evaluate the repeatability of $\mathrm{pH}$ and voltage drop. Fig 4 and fig 5 shows the voltage dropped with respect to time around the mortar plus bricks during these experiments. In both cases the voltage drop increases with passes of time [17]. The variation in the voltage is expressing the variation in resistance.

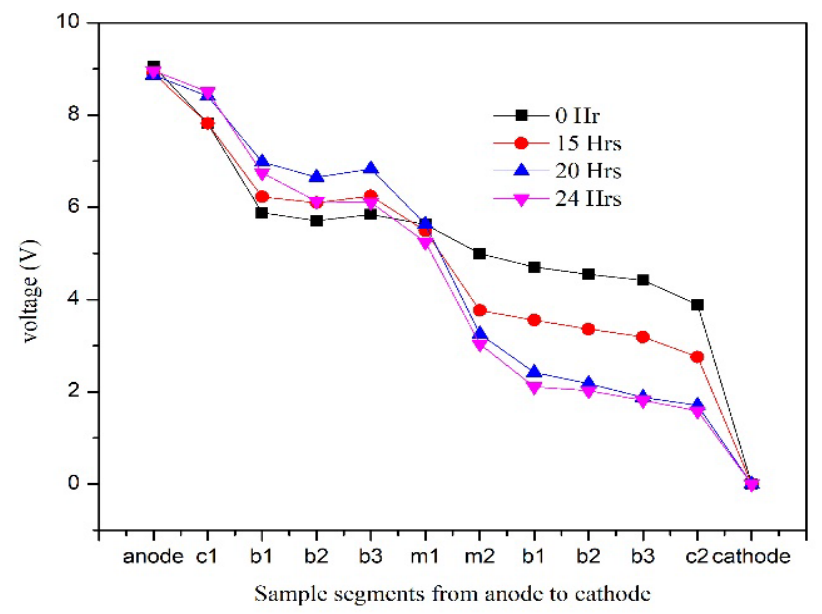

Fig 4. The voltage between electrodes during sponge experiment. The experiment is conducting for 24 hours with 9 voltage.

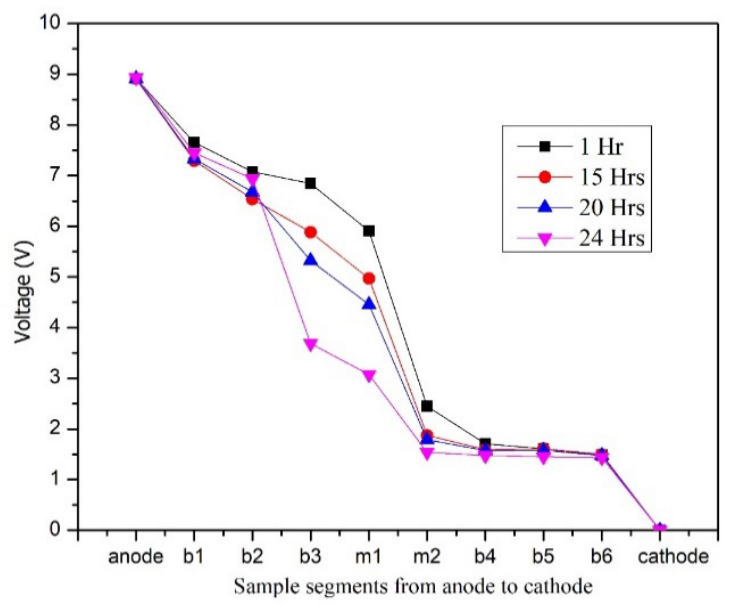

Fig 5. The voltage between electrodes during clay experiment. The experiment are conducting for 24 hours with 9 voltage

During the experiments the ion concentration are decreasing in the mortar plus bricks in the result increased the resistance. If we considered current is also constant in these experiments than ohm's law obey. Voltage is directly proportional to the resistance, increase the resistance increase voltage dropped around the sample [18]. 
The sponge and clay used in electrode compartments in the different experiment had different conditions. This interface cased in change in resistance in the sample, and voltage drop were different for experiments with same time and same voltage.

\subsection{Reference mortar plus bricks system}

Differences in salt concentration must be expected because bricks and mortar originate from a nonhomogeneous natural material, even though the bricks and mortar are produced from the same brickwork and mortar from the same batch or company. First of all we measured $\mathrm{Cl}$ ions and $\mathrm{Na}$ ions in the reference mortar plus bricks system because it is necessary to know the salts concentration in one mortar plus bricks without application diffusion and electric DC field. The $\mathrm{pH}$ of the reference mortar plus bricks are measured to compare after applied electric DC field [16]. The $\mathrm{Na}$ ions and $\mathrm{Cl}$ ions in the bricks part is higher than mortar section even though the mortar plus bricks is submerged in the same molar concentration of $\mathrm{NaCl}(2 \mathrm{M})$. The diffusion coefficient of the $\mathrm{NaCl}$ is 1.844 for $0.1 \mathrm{M}$. but $\mathrm{Na}$ and $\mathrm{Cl}$ ions concentration are differenced in the reference mortar plus bricks may be this difference occur due the difference in porosity (the porosity of brick is $30.77 \%$ and mortar is $8 \%$ ) [19].

\subsection{Removal vs conditions}

In the present work, totally four experiments were conducted with different condition and same voltage and duration. Which is already discuss in the materials and methods section. The $\mathrm{Cl}^{-}$concentration of all experiments show in fig 6 and $\mathrm{Na}$ ions concentration of all experiments show in fig 7.

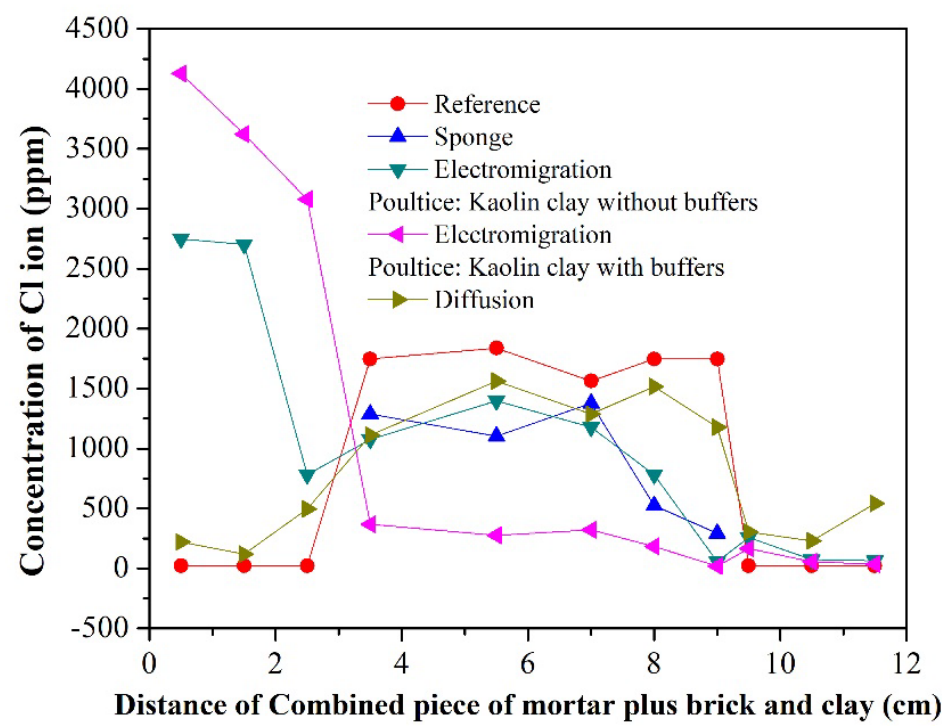

Fig 6. $\mathrm{Cl}$ ions concentration profiles of all experiment after diffusion and electrokinetic desalination for 24 hours.

As seen, there is a general tendency for the concentration of $\mathrm{Cl}$ ions are moved toward the anode side when we applied electric DC field. The reason is probably that chloride ions transport to the opposite polarity (negatives ions transport toward the positive side of electric DC field). In the sponge and kaolin clay without buffer experiments, the removal rate of chloride ions is less than as compared to kaolin clay with buffer experiment. Because during in all experiment acid and alkaline are produced at anode and cathode compartment, respectively.

The mean concentration of $\mathrm{Cl}$ ion in the reference mortar plus bricks was $8640.48 \mathrm{ppm}$ and the mean concentration of $\mathrm{Na}$ ion was $8736.14 \mathrm{ppm}$ and these values decreased in every segment during application of voltage. Chloride ions are expected to move toward the anode and sodium ions move to toward the cathode in the applied electric DC field. Concentration profile (fig) it is also seen that the removal rare of $\mathrm{Cl}$ ions is greater than the $\mathrm{Na}$ ions. The $\mathrm{Cl}$ ions and $\mathrm{Na}$ ions removal were measured in all experiment. The removal percentage of $\mathrm{Na}$ and $\mathrm{Cl}$ ions is shown in table 2.

In all experiment expect diffusion $\mathrm{pH}$ change around the sample, due to the electrode processes an increase in $\mathrm{pH}$ from the cathode end by the acid and a $\mathrm{pH}$ decrease from the anode end by alkaline. At the end of the experiment $\mathrm{pH}$ was between "10 to 11" in the clay next to cathode and in the clay next to the anode pH was between "5 to 6". Initially $\mathrm{pH}$ in the clay was about 8 . The clay had neutralized the acid produced at the anode.

The $\mathrm{pH}$ in the mortar plus bricks shows in figure 8 . The $\mathrm{pH}$ changes due to the electrokinetic processes in the mortar plus bricks. The pH was lower at anode side and higher at cathode side of mortar plus bricks [20]. 


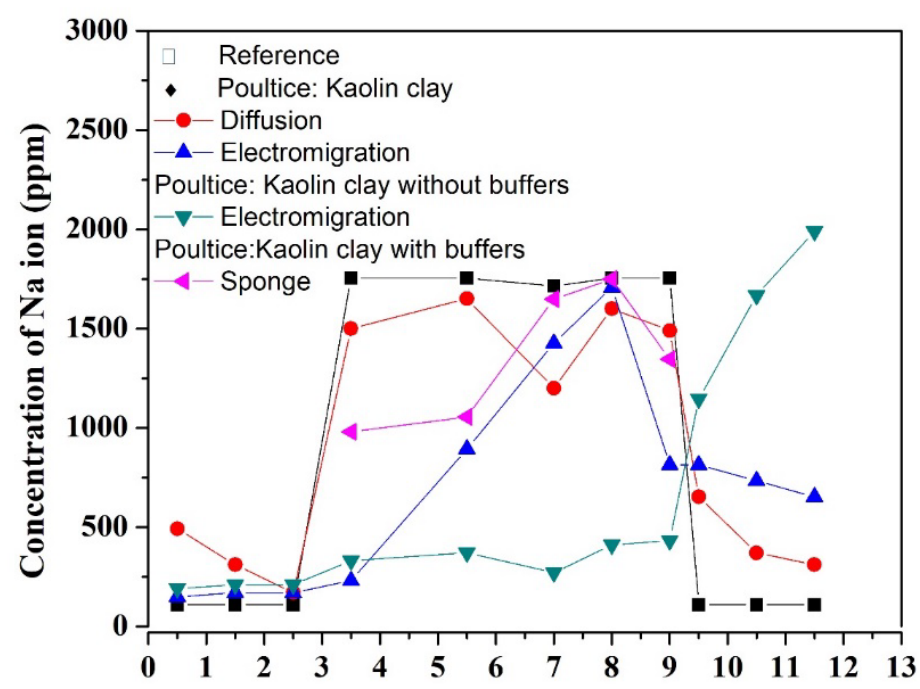

Distance of Combined piece of mortar plus brick and clay $(\mathrm{cm})$

Fig 7. Na ions concentration profiles of all experiment after diffusion and electrokinetic desalination for 24 hours.

Table 2. Removal efficiency of $\mathrm{Na}$ and $\mathrm{Cl}$ ions. Most efficient result was obtained with Electromigration Poultice: Kaolin clay with buffers

\begin{tabular}{ccc}
\hline Experiments & $\begin{array}{c}\text { Removal efficiency of } \mathrm{Cl}^{-} \\
(\%)\end{array}$ & $\begin{array}{c}\text { Removal efficiency of } \mathrm{Na}^{+} \\
(\%)\end{array}$ \\
\hline Diffusion & 22.97872 & 31.41792 \\
Sponge & 46.91489 & 41.90596 \\
Electromigration & 48.08511 & 64.22579 \\
Poultice: Kaolin clay without buffers & & 79.18729 \\
Electromigration & 86.48936 & \\
Poultice: Kaolin clay with buffers & & \\
\hline
\end{tabular}

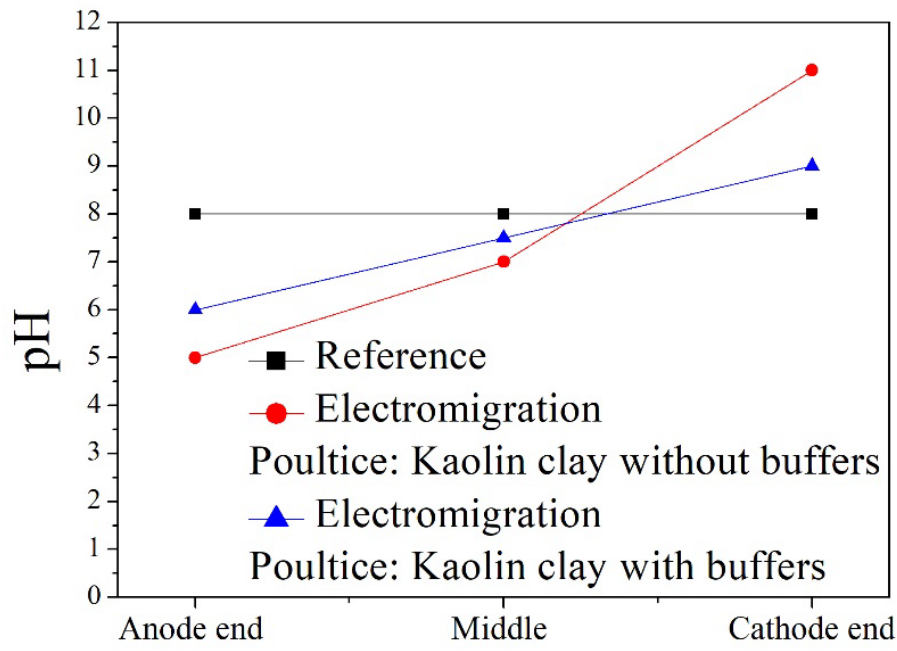

Fig 8. $\mathrm{pH}$ in mortar plus bricks system at the end of experiments

\section{Conclusions}

In this work total five experiments were performed for electrokinetic desalination. Five mortar plus brick system were used for different purpose, first sample was used as a reference, second sample was used to diffusion experiment (KK-D), third sample was used to perform electro-kinetic experiment with kaolin clay (KK-E), fourth sample was used to perform electro-kinetic experiment use buffering agents in kaolin clay and fifth sample was used to perform electro-kinetic treatment with sponge. Most of the experiments were performed with kaolin clay and sponge, electrodes and sponge were placed in the clay at the sides of bricks. Diffusion experiment was 
conducted so that the efficiency of electro-kinetics treatment could be compared. The electrokinetic desalination was very efficient and $86 \%$ removal of chloride and $80 \%$ removal of sodium was achieved with buffers and $\mathrm{pH}$ neutralized. The removal rate for $\mathrm{Cl}$ is highly influenced as compared to $\mathrm{Na}$ ions and it was found that the removal rate of $\mathrm{Na}$ ions was slower than $\mathrm{Cl}$ ions with same duration and voltage. The removal rate can be more efficient by increasing time duration of experiment.

\section{References}

[1] Ahl J, Lü X. Studying of salt diffusion behaviour in brick. Journal of materials science. 2007;42(7):25122520.

[2] Ottosen LM, Rörig-Dalgaard I. Desalination of a brick by application of an electric DC field. Materials and structures. 2009;42(7):961-971.

[3] Kamran K, Pel L, Sawdy A, Huinink H, Kopinga K. Desalination of porous building materials by electrokinetics: an NMR study. Materials and structures. 2012;45(1-2):297-308.

[4] Paz-Garcia JM, Johannesson B, Ottosen LM, Alshawabkeh AN, Ribeiro AB, Rodríguez-Maroto JM. Modeling of electrokinetic desalination of bricks. Electrochimica Acta. 2012;86:213-222.

[5] Ottosen LM, Rörig-Dalgård I. Electrokinetic removal of $\mathrm{Ca}\left(\mathrm{NO}_{3}\right)_{2}$ from bricks to avoid salt-induced decay. Electrochimica Acta. 2007;52(10):3454-3463.

[6] Garcia-Gutierrez M, Gomez-Lahoz C, Rodriguez-Maroto J, Vereda-Alonso C, Garcia-Herruzo F. Electrokinetic remediation of a soil contaminated by the pyritic sludge spill of Aznalcollar (SW, Spain). Electrochimica acta. 2007;52(10):3372-3379.

[7] Ottosen LM, Pedersen AJ, Rörig-Dalgaard I. Salt-related problems in brick masonry and electrokinetic removal of salts. Journal of Building Appraisal. 2007;3(3):181-194.

[8] Ruedrich J, Siegesmund S. Salt and ice crystallisation in porous sandstones. Environmental Geology. 2007;52(2):225-249.

[9] Matyscak O, Ottosen LM, Rörig-Dalgaard I. Desalination of salt damaged Obernkirchen sandstone by an applied DC field. Construction and Building Materials. 2014;71:561-569.

[10] Paz-García JM, Johannesson B, Ottosen LM, Ribeiro AB, Rodríguez-Maroto JM. Modeling of electrokinetic processes by finite element integration of the Nernst-Planck-Poisson system of equations. Separation and Purification Technology. 2011;79(2):183-192.

[11] Stryszewska T, Kańka S. The effects of salt crystallization in ceramic bricks in terms of line deformations. Procedia Engineering. 2017;193:120-127.

[12] Skibsted G, Ottosen LM, Jensen PE, Paz-Garcia JM. Electrochemical desalination of bricks-Experimental and modeling. Electrochimica Acta. 2015;181:24-30.

[13] Ottosen LM, Christensen IV. Electrokinetic desalination of sandstones for NaCl removal-test of different clay poultices at the electrodes. Electrochimica Acta. 2012;86:192-202.

[14] Elias ML, Cultrone G. On the use of sodium chloride and calcined diatomite sludge as additives to improve the engineering properties of bricks made with a clay earth from Jun (Granada, Spain). Minerals. 2019;9(1):64.

[15] Qasim M, Badrelzaman M, Darwish NN, Darwish NA, Hilal N. Reverse osmosis desalination: A state-ofthe-art review. Desalination. 2019;459:59-104.

[16] Rörig-Dalgaard I. Development of a poultice for electrochemical desalination of porous building materials: desalination effect and pH changes. Materials and structures. 2013;46(6):959-970.

[17] Abou-Shady A. Reclaiming salt-affected soils using electro-remediation technology: PCPSS evaluation. Electrochimica Acta. 2016;190:511-520.

[18] Kamran K, Van Soestbergen M, Pel L. Electrokinetic salt removal from porous building materials using ion exchange membranes. Transport in porous media. 2013;96(2):221-235.

[19] Paz-Garcia JM, Johannesson B, Ottosen LM, Ribeiro A, Rodríguez-Maroto J. Simulation-based analysis of the differences in the removal rate of chlorides, nitrates and sulfates by electrokinetic desalination treatments. Electrochimica Acta. 2013;89:436-444.

[20] Kirkelund GM, Jensen PE, Ottosen LM, Pedersen KB. Comparison of two-and three-compartment cells for electrodialytic removal of heavy metals from contaminated material suspensions. Journal of hazardous materials. 2019;367:68-76.

(C) 2021 by the author(s). This work is licensed under a Creative Commons Attribution 4.0 International License (http://creativecommons.org/licenses/by/4.0/). Authors retain copyright of their work, with first publication rights granted to Tech Reviews Ltd. 